\title{
Empirical Research on Total Factor Productivity of Agglomeration of Producer Services Industry
}

\author{
Li Wang \\ Guizhou University of Finance and Economics, Guiyang 550025, China. \\ 742920045@qq.com
}

\begin{abstract}
Based on panel data related to the producer services industry in 27 provincial capital cities in China from 2004 to 2014, this paper first uses location entropy index method and DEA-Malmquist index method to measure the level of producer service industry agglomeration and total factor productivity. The research conclusions show that the accumulation of productive service industry has a significant role in promoting total factor productivity, which is mainly due to the effect of technological progress. At the same time, scientific and technological investment has a significant positive effect on the improvement of total factor productivity. Finally, based on the conclusions, this paper puts forward relevant countermeasures and suggestions on the accumulation of producer service industry to promote the growth of total factor productivity.
\end{abstract}

Keywords: Productive Service Industry; Industrial Agglomeration; Total Factor Productivity.

\section{生产性服务业集聚对全要素生产率的实证研究}

\author{
王丽 \\ 贵州财经大学, 贵阳, 中国
}

摘 要：本文基于2004-2014年中国27个省会城市生产性服务业相关的面板数据, 首先运用区 位熵指数法和DEA-Malmqui st指数法分别测算了生产性服务业集聚水平和全要素生产率情况。 研究结论表明: 生产性服务业集聚对全要素生产率具有显著的促进作用, 这主要得益于技术 进步的作用; 同时, 科学技术投入对全要素生产率的提高也有显著的正向作用。最后, 针对 所得结论，本文提出了生产性服务业集聚促进全要素生产率增长的相关对策建议。

关键词：生产性服务业；产业集聚；全要素生产率.

\section{1. 前言}

随着中国进一步扩大对外开放，传统制造业已经逐渐跟不上中国快速前进的步伐，而生产性 服务业作为知识和技术密集型的高附加值服务业已经成为各城市经济发展竞相争夺的产业制 高点（宣烨，2017），对我国经济的增长也发挥着越来越重要的作用。近年来，我国生产性 服务业的发展进程加快, 但国际竞争力仍然较弱, 究其原因, 主要为过于依赖要素和资源的 投入，且面对我国逐渐丧失廉价劳动力的成本优势、发达国家在研发设计、市场营销等生产 性服务业领域占据主导地位以及产能过剩、环境约束等一系列问题, 提高我国生产性服务业 的全要素生产率成为一项紧要的任务。而生产性服务业集聚可以显著地促进地区全要素生产 率的提高（鹿坪, 2017)。同样, 彭娜（2014）通过研究发现, 我国产业集聚对生产性服务业 全要素生产率的分解效率技术进步在短期和长期都有促进作用。范剑勇和冯猛等 (2014) 得 出集聚效应对其全要素生产率并不完全具有正向作用, 而多样化集聚可以促进技术进步提升 的结论。袁丹和雷宏振 (2015) 通过实证分析, 认为多样化集聚是促进生产性服务业全要素 生产率增进的主要动力, 而专业化集聚对我国生产性服务业的纯技术效率具有显著的正向作 用。

在对全要素生产率的研究方面, 国内学者起步较晚, 多集中于从全国范围方面研究, 且没有 得出一致性的结论。一些学者通过研究发现, 我国全要素生产率呈上升趋势, 但存在地区不 
平衡性, 也有学者认为其整体呈下降趋势, 等等。而对于按各地区的生产性服务业集聚与全 要素生产率相结合的研究却相对较少。基于上述原因, 本文选取 2004-2014 年我国生产性服 务业相关的面板数据, 测算了我国除兰州、拉萨、南昌和昆明外的（由于数据缺失） 27 个省 会生产性服务业的集聚水平和全要素生产率，并对二者进行回归分析，实证检验了生产性服 务业集聚对全要素生产率的影响情况。

\section{2. 研究设计}

\section{1. 模型设定}

本文基于数据的可得性, 利用我国 2004-2014 年 27 个省会城市的面板数据, 对生产性服务业 集聚与全要素生产率之间的作用关系进行实证分析，建立如下模型：

$$
\mathrm{TFP}_{\mathrm{it}}=\beta_{0}+\beta_{1} \mathrm{CTR}_{\mathrm{it}}+\beta_{2} \mathrm{LQ}_{\mathrm{it}}+\beta_{3} \mathrm{Ln}\left(\mathrm{CS}_{\mathrm{it}}\right)+\beta_{4} \mathrm{SCC}_{\mathrm{it}}+\varepsilon_{\mathrm{it}}
$$

其中, TFP 表示全要素生产率, LQ 表示用区位熵指数衡量的专业化集聚, CTR 为用各地区年末 城镇人口占总人口的比重测算的城镇化率, CS 为用各地区高校在校生人数并对其取对数来衡 量的人力资本，SCC 用政府科学技术支出来衡量各地区的科学技术投入。

2.2. 变量选取及数据来源

2.2.1. 被解释变量

全要素生产率 (TFP), 本文采用 DEA-Malmquist 指数法来对我国省会的全要素生产率进行估 算。该方法可以测算多时期、多投入、多产出下的全要素生产率。

2.2.2. 解释变量

区位熵指数（LQ）, 用来衡量专业化集聚, 能较好的反映出一个地区某产业与全国发展的差 距; 城镇化率 (CTR), 反映城市多样化集聚。具有互补性的异质性企业的集聚, 能够促进企 业研发与创新, 提供更加多样化的投入品, 从而使中间成本降低, 促进生产效率的增长 (Jacobs, 1969）。参考相关学者的做法, 用各地区年末城镇人口占总人口的比重对其进行测算。

2.2.3. 控制变量

人力资本 $(\mathrm{CS})$, 是影响全要素生产率的重要因素, 为了减少不考虑这方面因素可能造成的 误差, 借鉴袁丹等学者的研究, 本文用各地区高校在校生人数来衡量人力资本; 科学技术投 入 (SCC), 考虑到科学技术的投入能直接提升全要素生产率, 故借鉴以往学者的研究, 用政 府在科学技术上的支出来衡量各地区的科学技术投入;

由于南昌、昆明、兰州和拉萨这四个城市的数据缺失, 故共测算 27 个城市。以上数据均来源 于 2004-2014 年《中国统计年鉴》、《中国第三产业统计年鉴》、《中国城市统计年鉴》以 及各城市考察年份期间内的城市年鉴。

\section{3. 空间计量分析}

3.1. 产业集聚的测度

关于产业集聚的测度方法很多, 考虑到数据的可得性以及研究的目的性, 本文选取区位商指 数来衡量生产性服务业的专业化程度, 且能较好的反映一个地区某产业相对于全国发展的差 距。计算公式为:

$$
\mathrm{LQ}_{\mathrm{ij}}=\frac{\mathrm{q}_{\mathrm{ij}} / \mathrm{q}_{\mathrm{j}}}{\mathrm{Q}_{\mathrm{i}} / \mathrm{Q}}
$$

其中, $q_{i j}$ 表示 $j$ 地区 $i$ 产业的产值、就业人数等, $q_{j}$ 表示 $j$ 地区的总产值、总就业人数等, $Q_{i}$ 表示全国 $i$ 产业的产值、就业人数等, $Q$ 表示全国总产值、总就业人数等。当 $L Q_{i j}>1$ 时, 表 示 $\mathrm{j}$ 地区 $\mathrm{i}$ 产业的专业化集聚程度高, 相对于全国为优势产业, 值越大, 则优势越明显。 
表1.2004-2014年省会城市生产性服务业区位熵指数

\begin{tabular}{|c|c|c|c|c|c|c|c|c|c|c|c|c|}
\hline 省会城市 & 2004 & 2005 & 2006 & 2007 & 2008 & 2009 & 2010 & 2011 & 2012 & 2013 & 2014 & 平均值 \\
\hline 北京 & 2.78 & 2.85 & 2.84 & 2.72 & 2.83 & 2.91 & 2.94 & 3.38 & 2.90 & 2.37 & 2.28 & 2.80 \\
\hline 广州 & 1.50 & 1.51 & 1.58 & 1.56 & 1.55 & 1.61 & 1.57 & 1.66 & 1.34 & 1.83 & 3.47 & 1.74 \\
\hline 上海 & 1.55 & 1.98 & 1.71 & 1.81 & 1.80 & 1.85 & 1.91 & 1.92 & 1.80 & 2.05 & 2.29 & 1.88 \\
\hline 哈尔滨 & 1.42 & 1.22 & 1.36 & 1.46 & 1.44 & 1.52 & 1.63 & 1.37 & 1.16 & 1.12 & 1.35 & 1.37 \\
\hline 乌鲁木齐 & 1.44 & 1.11 & 1.32 & 1.31 & 1.35 & 1.48 & 1.46 & 1.74 & 1.71 & 1.62 & 1.29 & 1.44 \\
\hline 长春 & 0.90 & 1.43 & 1.28 & 1.45 & 1.44 & 1.48 & 1.43 & 1.36 & 1.35 & 0.96 & 1.02 & 1.28 \\
\hline 西宁 & 0.96 & 0.99 & 0.98 & 1.06 & 1.42 & 1.32 & 1.98 & 1.91 & 1.29 & 1.40 & 1.32 & 1.33 \\
\hline 合肥 & 1.12 & 0.68 & 1.33 & 0.92 & 0.97 & 1.03 & 1.18 & 1.04 & 1.02 & 0.90 & 0.94 & 1.01 \\
\hline 重庆 & 0.83 & 0.67 & 0.73 & 0.75 & 0.80 & 0.81 & 0.82 & 0.76 & 1.75 & 1.60 & 1.63 & 1.01 \\
\hline 平均值 & 1.22 & 1.25 & 1.39 & 1.38 & 1.39 & 1.41 & 1.41 & 1.44 & 1.38 & 1.40 & 1.51 & \\
\hline
\end{tabular}

如表 1 所示，从横向平均值来看，我国生产性服务业的集聚水平在 2004-2014 年间呈波浪式 上升趋势。从纵向来看, 我国生产性服务业的集聚水平整体较高, 均值均在 1 以上。而具体 来看, 区位熵指数主要可以分为两种类型（如表 1 所示）：第一类为生产性服务业区位摘指 数在考察区间内连续在 1 以上。北京、乌鲁木齐、哈尔滨等城市在 11 年间的区位熵指数连续 大于 1 , 表明这些城市的生产性服务业的专业化集聚水平较高, 相对于全国具有比较优势。第 二类为在考察区间内生产性服务业区位熵指数在 1 的附近呈现波动性变化。如西宁在 20042006 年间，重庆在 2004-2011 年间，区位熵指数均小于 1, 但在随后至 2014 年中则大于 1 , 又如福州、成都、合肥等城市在考察区间内, 区位熵指数在 1 的附近上下波动。表明这些城 市的生产性服务业集聚水平相对于全国较低，比较优势不稳定。

3. 2生产性服务业效率的测度

本文采用 DEA-Malmquist 指数法来对我国省会城市生产性服务业的全要素生产率进行估算, 同时将全要素生产率分解成技术效率和技术进步两个指数, 挖掘其变化背后的原因。则从 $\mathrm{t}$ 时期到 $(t+1)$ 时期，全要素生产率具体的计算公式为:

$$
M\left(X_{\mathrm{t}}, Y_{\mathrm{t}}, X_{\mathrm{t}+1}, Y_{\mathrm{t}+1}\right)=\sqrt{\frac{D_{\mathrm{t}}\left(X_{\mathrm{t}+1}, Y_{\mathrm{t}+1}\right) * D_{\mathrm{t}}+D_{\mathrm{t}+1}\left(X_{\mathrm{t}}, Y_{\mathrm{t}}\right)}{D_{\mathrm{t}}\left(X_{\mathrm{t}}, Y_{\mathrm{t}}\right) * D_{\mathrm{t}+1}\left(X_{\mathrm{t}+1}, Y_{\mathrm{t}+1}\right)}}=\mathrm{TEC} * \mathrm{TCH}
$$

其中, $\left(X_{t}, Y_{t}\right)$ 表示 $t$ 时期的投入向量, $\left(X_{t+1}, Y_{t+1}\right)$ 表示 $(t+1)$ 时期的产出向量, $D_{t}\left(X_{t}\right.$, $\left.Y_{t}\right)$ 和 $D_{t+1}\left(X_{t+1}, Y_{t+1}\right)$ 分别表示参照 $t$ 时期和 $(t+1)$ 时期技术的投入产出向量的距离函数, $\mathrm{TEC}$ 为技术效率指数, TCH 为技术进步指数。产出变量为各地区的产值（万元）, 并按照价格 指数将其折算为 2004 年的不变价。投入变量包括劳动力投入和资本投入, 劳动力投入用各地 区年末就业人数（万人）衡量, 资本投入用各地区的资本存量（万元）衡量, 并采用国内外 较为广泛使用的永续盘存法对其进行估算。

通过上述计算后, 若 $M>1$, 则表明从 $t$ 时期到（ $t+1$ ) 时期, 其全要素生产率呈上升趋势。

表2. 2004-2014年省会城市生产性服务业全要素生产率平均值

\begin{tabular}{|c|c|c|c|}
\hline 省会城市 & 技术进步 $(\mathrm{TCH})$ & 技术效率 $(\mathrm{TEC})$ & 全要素生产率 $(\mathrm{TFP})$ \\
\hline 合肥 & 1.1271 & 0.9728 & 1.0683 \\
\hline 杭州 & 1.1045 & 0.9579 & 1.0129 \\
\hline 成都 & 0.9874 & 1.0147 & 0.9426 \\
\hline 武汉 & 0.9599 & 1.0816 & 0.9838 \\
\hline 南京 & 1.0870 & 1.0181 & 1.0357 \\
\hline 贵阳 & 1.1310 & 1.0350 & 1.1318 \\
\hline 平均值 & 1.1326 & 1.0297 & 1.1273 \\
\hline 总平均值 & 1.0693 & 1.0303 & 1.0462 \\
\hline
\end{tabular}

按照全要素生产率的分解情况, 可以将省会城市分为三类: 第一类为技术效率的变化率小于 1 , 但技术进步的变化率大于 1 , 且技术进步的上升幅度大于技术效率的下降幅度, 这使得全 要素生产率大于 1 , 出现正向增长, 这些城市有合肥、郑州、杭州和沈阳。第二类为技术进步 的变化率小于 1 , 技术效率的变化率大于 1 , 但技术进步的下降幅度大于技术效率的上升幅度, 
这使得全要素生产率小于 1 , 这些城市有成都、武汉、乌鲁木齐、北京、福州、太原和西宁。 第三类为技术进步的变化率大于 1 , 技术效率的变化率也大于 1 , 二者的共同作用下，使得全 要素生产率呈现正向增长, 这些城市有呼和浩特、南宁、重庆、贵阳、西安、银川、长沙、天 津、石家庄、上海、南京、济南、广州、海口、长春和哈尔滨。

3. 3生产性服务业集聚对全要素生产率的实证分析

3. 3. 1 . 单位根检验

表 3 为对模型中相关变量进行的 LLC 和 Fisher-ADF 单位根检验, 结果显示, 各变量均通过了 在 $1 \%$ 水平下的单位根检验, 表明各变量时间序列是平稳的。

表3. 模型的单位根检验结果

\begin{tabular}{|c|c|c|}
\hline 变量 & Fisher-ADF检验 & LLC检验 \\
\hline TFP & $204.5833^{* * *}$ & $-4.2865^{* * *}$ \\
\hline CTR & $197.3750^{* * *}$ & $-4.4729^{* * *}$ \\
\hline LQ & $146.5510^{* * *}$ & $-7.7098^{* * *}$ \\
\hline CS & $134.3005^{* * *}$ & $-5.5786^{* * *}$ \\
\hline SCC & $219.4599^{* * *}$ & $-3.1768^{* * *}$ \\
\hline
\end{tabular}

注: ***、**和*分别表示变量系数通过 $1 \%$ 、 $5 \%$ 和 $10 \%$ 的显著性检验。

3.3.2. 实证检验

根据所建模型, 分别进行固定效应和随机效应检验, 检验结果如表 4 所示。由于 Hausman 检 验 $\mathrm{P}$ 值均小于 0.5 , 故固定效应更为有效。其中, 第 (1)、（2）列只对解释变量多样化集聚 (CTR) 和专业化集聚 (LQ) 进行检验。结果显示, CTR 和 LQ 均在 $1 \%$ 的水平下显著, 说明生 产性服务业集聚对于 TFP 的增长具有显著地正向作用，生产性服务业的集聚使得其在技术、 前沿知识等方面具有优势，进而促进 TFP 的提升。第（3）、（4）列在上面模型的基础上, 加入了 CS 这一控制变量。此时, CTR 和 LQ 仍然在 $1 \%$ 的水平下显著, 而 CS 虽然实证结果为 正, 但在模型检验中不显著, 这可能与在校大学生成为人力资本需要一个过程, 从而存在滞 后效应有关。第 (5)、（6）列将控制变量 CS 和 SCC 加入到模型中进行检验。结果显示, 虽 然 CTR 的实证结果为正, 但在模型中没有通过检验, 而 LQ 检验通过, 仍然在 $1 \%$ 的水平下显 著, 说明 LQ 相对 CTR 对 TFP 的作用更显著。CS 依旧没有通过检验。但 SCC 在 1\%的水平下显 著。这表明 SCC 有利于企业研发和自主创新, 对 TFP 的作用十分显著。

表4. 中国省会城市产业集聚与生产性服务业全要素生产率关系检验结果

\begin{tabular}{|c|c|c|c|c|c|c|}
\hline & $\begin{array}{c}\text { 随机效应 } \\
(1)\end{array}$ & $\begin{array}{c}\text { 固定效应 } \\
(2)\end{array}$ & $\begin{array}{c}\text { 随机效应 } \\
(3)\end{array}$ & $\begin{array}{c}\text { 固定效应 } \\
(4)\end{array}$ & $\begin{array}{c}\text { 随机效应 } \\
(5)\end{array}$ & $\begin{array}{c}\text { 固定效应 } \\
(6)\end{array}$ \\
\hline \multirow{2}{*}{ CTR } & 0.0044 & $0.1428^{* * *}$ & 0.0031 & $0.8529^{* * *}$ & $-0.3352^{* *}$ & 0.1183 \\
& $(0.03)$ & $(3.58)$ & $(0.02)$ & $(3.54)$ & $(-1.95)$ & $(0.39)$ \\
\hline \multirow{2}{*}{ LQ } & $0.1264^{* * *}$ & $0.2316^{* * *}$ & $0.1262^{* * *}$ & $0.2183^{* * *}$ & $0.1234^{* * *}$ & $0.2138^{* * *}$ \\
& $(3.48)$ & $(5.24)$ & $(3.47)$ & $(5.18)$ & $(3.44)$ & $(5.20)$ \\
\hline \multirow{2}{*}{ CS } & & & 0.0145 & 0.0304 & -0.3357 & 0.0243 \\
& & & $(0.92)$ & $(1.58)$ & $(-0.22)$ & $(1.25)$ \\
\hline \multirow{2}{*}{ SCC } & & & & & $0.0381^{* * *}$ & $0.0416^{* * *}$ \\
& & & & & $(4.24)$ & $(3.97)$ \\
\hline
\end{tabular}

注: ***、**和*分别表示变量系数通过 $1 \%$ 、5\%和 $10 \%$ 的显著性检验。 


\section{4. 结论与对策建议}

\section{1. 结论}

本文运用我国 2004-2014 年 27 个省会城市的面板数据, 利用区位熵指数法和 DEA-Malmquist 指数法分别测算出我国生产性服务业集聚水平和全要素生产率的情况，通过对二者之间关系 的实证分析, 得出以下几点结论:

(1)总体上看, 我国生产性服务业的集聚水平在考察区间内呈波浪式上升趋势, 平均值从 2004 年的 1.22 上升到 2014 年的 1.51 , 且各省会城市的区位熵指数均值也都在 1 以上。一线发达 城市的集聚水平较高, 如北京、上海、广州等，但部分城市的集聚程度，如福州、呼和浩特、 合肥等，与一线发达城市仍然有一定的差距。

（2）我国 27 个省会城市全要素生产率的年平均增长率为 $4.62 \%$, 整体呈上升趋势。其中，技 术进步和技术效率的年平均变化率均为正值, 二者共同促进了全要素生产率的增长, 且技术 进步的作用更为明显。

(3) 生产性服务业集聚对全要素生产率的提高具有促进作用, 这主要得益于技术进步的正向 影响。另外, 控制变量中人力资本对全要素生产率的影响作用不显著, 这可能是因为在校大 学生成为人力资本需要一个过程，从而存在滞后效应有关。而科学技术投入有利于企业研发 和自主创新，对全要素生产率的提高具有显著地正向影响。

4. 2. 对策建议

(1) 全要素生产率的增长主要得益于技术进步的提高, 而其主要来自于科学技术的投入以及 高素质的人才，因此企业应加大研发投入和自主创新，同时充分利用当地高校的人力资源， 提高创新意识和研发能力。

（2）生产性服务业集聚对全要素生产率具有显著地正向作用，政府应当采取政策措施以促进 生产性服务业的集聚水平，如加大配套基础设施建设、城市教育与高素质人才培养等的投资。 此外，科学技术的投入对全要素生产率增长有着显著地促进作用，因此，政府应加强知识产 权保护和技术创新激励，进一步完善相关的法律法规，促进生产性服务业的健康发展。

\section{Acknowledgements}

Thank you for Guizhou University of Finance and Economics 2017 Student Science Research Grant Project (Project number: 2017ZXSY49).

\section{References}

[1]. Jacobs J, et al. The Economy of Cities[M].New York:Random House,1969.

[2]. Hansen, et al. The Strategic Role Producer Services in Regional Development[J].International Regional Science,1994:16(1):187-195.

[3]. Porter M. E, et al. Clusters and the New Economics of Competition[J]. Harvard Business Review,1998,96(6):77-90.

[4]. Coffey W J, et al. The Geographies of Producer Services[J].Urban Geograhy,2000,21(2):170183.

[5]. Goodman, Steadman, et al. Services: Business Demand Rivals Consumer Demand in Driving Growth[J]. Monthly Labor Review,2002,125(4):3-9.

[6]. Fujita, M, Thisse J F, et al. Economics of Agglomeration: Cites, Industrial Location and Regional Growth[M]. Cambridge University Press,2002.

[7]. Kim M K, Harris T R, Vusovic S, et al. Efficiency Analysis of the US Biotechnology Industry: Clustering Enhances Productivity[J]. AgBioForum,2009,12(3):422-436. 
[8]. Grahanm D, et al. Identifying Urbanization and Localization Externalities in Manufacturing and Service Industries[J]. Papers in Regional Science,2009, 88(1):63-85. 